\title{
Analysis of Clinical-Radiological-Pathological Factors in FN/ SFN Bethesda Category Thyroid Nodules, Contribution of FNAB Repeat, Single Center Experience
}

\author{
Ramazan Ucak, ${ }^{1}$ (D) Deniz Turkyilmaz, ${ }^{2}$ (D) Nurcihan Aygun, ${ }^{3}$ (i) Cennet Sahin, ${ }^{2}$ (1) Banu Yilmaz Ozguven, \\ Fevziye Kabukcuoglu, ${ }^{1}$ (D) Mehmet Uludag ${ }^{3}$ \\ 'Department of Pathology, University of Health Sciences, Sisli Hamidiye Etfal Teaching and Research Hospital, Istanbul, Turkey \\ 2Department of Radiology, University of Health Sciences, Sisli Hamidiye Etfal Teaching and Research Hospital, Istanbul, Turkey \\ ${ }^{3}$ Department of General Surgery, University of Health Sciences, Sisli Hamidiye Etfal Teaching and Research Hospital, Istanbul, Turkey
}

\begin{abstract}
Objectives: Follicular neoplasm/suspected follicular neoplasm (FN/FNS) Bethesda Category (BC)-4 group cases are known as the gray zone. Nodules diagnosed in cytology are excised. However, very few of these nodules are malignant. Our aim is to investigate the usability of clinical-radiological-pathological parameters to reduce unnecessary surgery. In addition, we questioned the benefit of repeating fine-needle aspiration biopsy (rFNAB) in these nodules, which is not recommended, but performed for clinical or patient-related reasons.

Methods: The files of all thyroid FNAB patients conducted in our institution between January 2014 and September 2020 were scanned in the database. In our study, 185 (5.1\%) nodules with cytology results of which were classified as FN/FNS were identified among 3624 nodules that were applied FNAB during this period. Twenty-eight patients were excluded from the study group. 157 nodules belonging to 157 patients between the ages of 21 and 82 years who were operated and met the study criteria were identified from patients with these nodules. The files of all patients were scanned and the results of age, gender, ultrasonographic nodule characteristics, FNAB repeat, type of surgery, and postoperative pathology were recorded. All data were analyzed by comparing them with nodule features. SPSS 15.0 for Windows program was used for statistical analysis.

Results: A significant correlation was found between the incidence of malignancy and male gender and hypervascularization $(p=0.017$ and $p=0.002$, respectively). Malignancy was less in nodules larger than $2 \mathrm{~cm}(p=0.014)$. There was no relationship between other clinical and radiological features and malignancy. In 29 nodules with rFNAB, a significant correlation was found between malignancy and advanced age (52.9-years-old), presence of nodules smaller than $2 \mathrm{~cm}$ and hypervascularization ( $p=0.047$, $\mathrm{p}=0.047$, and $\mathrm{p}=0.030$, respectively).

Conclusion: We recommend careful review of patients with hypervascular, hypoechogenic, and microcalcific BC-4 nodules (male gender and older patients at greater risk). Because of the serious risk of malignancy, patients with these features should be prepared for patient management with total thyroidectomy after examination with frozen section applied to the nodule during the operation. Keywords: Bethesda; FN/SFN category; repeat fine-needle aspiration biopsy; suspicious USG features; thyroid.

Please cite this article as "Ucak R, Turkyilmaz D, Aygun N, Sahin C, Yilmaz Ozguven B, Kabukcuoglu F, et al. Analysis of Clinical-RadiologicalPathological Factors in FN/SFN Bethesda Category Thyroid Nodules, Contribution of FNAB Repeat, Single Center Experience. Med Bull Sisli Etfal Hosp 2021;55(2):237-246".
\end{abstract}

Address for correspondence: Ramazan Ucak, MD. Saglik Bilimleri Universitesi Sisli Hamidiye Etfal Egitim ve Arastirma Hastanesi, Patoloji Anabilim Dali, Istanbul, Turkey

Phone: +90 2122370000 (5016) E-mail: drramazanucak@hotmail.com

Submitted Date: March 30, 2021 Accepted Date: April 14, 2021 Available Online Date: July 02, 2021

${ }^{\circ}$ Copyright 2021 by The Medical Bulletin of Sisli Etfal Hospital - Available online at www.sislietfaltip.org

OPEN ACCESS This is an open access article under the CC BY-NC license (http://creativecommons.org/licenses/by-nc/4.0/) 
B efore the establishment of the Bethesda categories, the diagnosis of "follicular neoplasm" (FN) was known as the area representing the "gray zone" in thyroid cytology, as only $20 \%$ of it identified nodules that were malignant when examined following surgical excision. ${ }^{[1]}$ In The Bethesda System for Reporting Thyroid Cytopathology, hypercellular thyroid cytology in microfollicular structure is defined as $\mathrm{FN} /$ follicular neoplasm suspicion (FNS) in category $4 .{ }^{[2]}$ Updated in 2017 Bethesda with the inclusion of innovations. ${ }^{[3]}$ In the process, Bethesda Category (BC)-4 emerged as one of the most controversial categories of this system due to the variability of both incidence and post-operative malignancy rates. ${ }^{[4-6]}$ Nowadays, we know more about the true nature of BC- 4 nodules as excision of BC- 4 nodules is becoming more common. ${ }^{[7]}$ Because, according to American Thyroid Association (ATA) 2015 criteria, most of these nodules are excised. ${ }^{[8]}$

The cytological definition of this category is basically cellularity-rich aspirated cases consisting of follicular cells showing cell crowding or microfollicle formation. ${ }^{[3]}$ Histopathologically, many benign or malignant entities have been described in nodules excised after fine-needle aspiration biopsy (FNAB) diagnosis FN. These are lesions that show a follicular pattern such as nodular goiter (NG), follicular adenoma (FA), follicular variant of papillary carcinoma (FVPC), and follicular carcinoma (FC). These listed lesions have common cytomorphological features and are often indistinguishable from FNAB examination alone. ${ }^{[2]}$

The majority of cases (up to 35\%) are not neoplasms, but most commonly multinodular goiters (MNG) and consist of hyperplastic proliferations of follicular cells corresponding to cellularity determined in cytology. Most cases of SFN occur as FAs or adenomatoid nodules of MNG. Malignant cases come next, most are follicular pattern carcinomas (mostly FVPC and less FC). ${ }^{[2]}$ There are no definitive clinical or cytological criteria to distinguish between benign and malignant lesions in the FN category. Molecular studies and diagnostic use of immunohistochemical markers are limited. Therefore, the uncertainty of the nature of these lesions is a reality ${ }^{[9]} \mathrm{Cy}$ tological material obtained from FNAB cannot be sufficient to differentiate between $\mathrm{FCs}$, Fas, and hyperplastic nodules. Because, in the diagnosis of $\mathrm{FC}$, it is essential to determine capsular invasion and/or angioinvasion. The final result is only possible after histopathological examination. ${ }^{[10]}$

Only $15-20 \%$ of patients with a cytological diagnosis of FN will have a malignant result on histological examination, thus making surgery unnecessary in up to $85 \%$ of patients. ${ }^{[9]}$ Its incidence has been reported between $1.5 \%$ (5) and $16.8 \%$ in the literature. ${ }^{[6]}$ In a meta-analysis study, it was found with an average frequency of $10.1 \%{ }^{[4]}$
In the original Bethesda system, risk of malignancy (ROM) was $25-40 \%$ before the NIFTP category. With the addition of this category, it was further reduced by $10-40 \%{ }^{[3]}$

The general features we have tried to explain so far, the fact that the definitive histopathological diagnoses of these nodules are mostly benign even if they are neoplasia, and the wide range of incidence and malignancy rates clearly reveal that more predictive criteria should be used when deciding on surgical excision of these nodules. Selection is important for the surgery of these nodules, since the ROM is very variable and primarily benign lesions such as MNG or FAs in resection diagnoses. In the literature, there are not many studies investigating the predictive approach toward other criteria other than studies on size as a surgical criterion in these nodules. ${ }^{[1]]}$ For this purpose, USG properties of BC-4 nodules are also being investigated. If patient management is possible in this category, it has been updated as molecular testing and lobectomy ${ }^{[3]}$ Repeat FNAB (rFNAB) application is generally not used in BC-4 aspirations. There are very few studies in the literature regarding the comparison of $\mathrm{rF}$ NAB for these nodules and there are not enough data. ${ }^{[10-13]}$ Because, in the guidelines and in the Bethesda system, the application of $\mathrm{rFNAB}$ is mostly recommended for $\mathrm{BC}-1$ and 3 nodules. ${ }^{[3]}$ When FNAB results in FN/FNS, management decision is not easy. In these cases, it is not uncommon to perform diagnostic hemi-thyroidectomy, sometimes a more conservative approach is preferred and rFNAB is performed. However, none of these scenarios seem ideal. It is known that total thyroidectomy in thyroid tissue with a malignant lesion and surgical resection in a benign lesion is over-treatment. Therefore, hemi-thyroidectomy is rarely preferred for indeterminate thyroid nodules. The benefit of rFNAB in indeterminate nodules, like hemi-thyroidectomy, is uncertain in terms of its contribution to patient management. If the rF$N A B$ result is $B C-2,5,6$, the management recommendations are clearer, the test was useful. However, when it results in $\mathrm{BC}-1,3,4$ categories, the process has gone back to the beginning and has been useless. ${ }^{[14]}$

On the basis of all this information, we have provided for BC-4 nodules, we investigated our patients in our institution, clinical-radiological factors that can be used to decide on patient management, surgical excision selection, and the possible contribution of rFNAB as a comparative analysis-statistical study.

\section{Methods}

The files of all thyroid FNAB patients conducted in our institution between January 2014 and September 2020 were scanned in the database. The histopathological and clinical results of these patients obtained from all available sources 
were recorded. In our study, 185 (5.1\%) nodules with cytology results of which were classified as FN/FNS were identified among 3624 nodules that were applied FNAB during this period. Nodules with a lack of data, continuing their treatment in another institution, and no definite pathological diagnosis after excision were excluded from the study. Nodules with FNAB results conforming to BC-4 definitions, without speculation on excision diagnoses, and with regular clinical and radiological data were included in the study. Twenty-eight patients were excluded from the study group. 157 nodules belonging to 157 patients between the ages of 21 and 82 years who were operated and met the study criteria were identified from patients with these nodules.

Thyroid function tests, neck USG of all patients were performed. The files of all patients were scanned and the results of age, gender, ultrasonographic nodule characteristics, FNAB repeat, type of surgery, and postoperative pathology were recorded. Patients with a personal or family history of cancer, a history of irradiation to the head and neck region, who received thyroid hormone therapy, or who had undergone previous thyroid surgery were not included in the study. Neck USG and FNAB of the patients were performed by a radiologist with at least 10 years of experience in this field, and an USG device with 5-12 MHz linear transducer was used for the procedure. The procedure was performed by bringing the neck of the patient lying in the supine position to hyperextension as a standard using an USG-guided $23 \mathrm{G}$ needle. We determined the radiological (USG) characteristics of all nodules. The main features were nodule size, edge irregularity, internal structure, echogenicity, presence of calcification, vascularization, and halo loss. ${ }^{[15,16]}$ In our institution, BC-4 nodules are excised according to ATA guidelines, but FNAB is repeated when there is clinical-radiological-cytological incompatibility.

The preparations stained with routine PAP, prepared by conventional cytology, liquid-based cytology and additionally cell block methods (two examples of cases are shown in Figs. 1 and 2), were examined by pathologists with high cytology experience, one of which was an endocrine organ pathologist and liquid-based cytology methods, were examined by pathologists with high cytology experience, one of which was an endocrine organ pathologist. Cell block aspirates were analyzed in serial sections. In the evaluation, categorization was done in accordance with Bethesda 2017 criteria. Accordingly, aspirates consisting of thyrocytes showing hypercellular, cell crowding or microfollicle formation were categorized in this group. Colloid was too little or minimal. Cell-rich aspirates with mild atypical nuclear changes were included in this group according to the latest definitions. In addition, non-colloid, hypercellular aspirates rich in Hurthle cells showing atypia were accepted. ${ }^{[3]}$

\section{Statistical Analysis}

SPSS 15.0 for Windows program was used for statistical analysis (Manufacturer city-states where the company is located in Istanbul/Turkey) descriptive statistics; number and percentage for categorical variables, and numerical variables as mean, standard deviation, minimum, maximum, and median. The rates in independent groups were compared using the Chi-square test. Since the numerical variable did not meet the normal distribution condition, comparisons of two independent groups were made using the Mann-Whitney U-Test. Statistical significance level of alpha was accepted as $p<0.05$.

\section{Results}

Our BC-4 ratio in aspirations of all nodules was $5.1 \%$ (185/3624 nodules). Of these 185 nodules, 157 were operated (84.8\%). 106 of 157 cases were male and 51 were female. $77.4 \%(2804 / 3624)$ of these FNABs were female patients, and unlike BC-4, in other Bethesda categories, there were more female patients. The mean age in all cases (including benign/malignant groups) was approximately $45.9 \pm 13.9$ years. There was the smallest $0.7 \mathrm{~cm}$ and the largest $10 \mathrm{~cm}(20.6 \pm 13.2)$ nodule size. Malignancy was detected in 61 nodules (38.9\%). A significant correlation was found between the incidence of malignancy and male gender and hypervascularization $(p=0.017$ and $p=0.002$, respectively). Malignancy was less in nodules larger than $2 \mathrm{~cm}(p=0.014)$. There was no relationship between other clinical and radiological features and malignancy (Table 1).

rFNAB was performed in 29 cases (18.5\%). When we look at their BC distribution (Table 2), the new cytology of seven cases was included in the category to be operated (BC4, 6 nodules/BC-6, and one nodule). Of these, 4 (57.1\%) were malignant after excision. In the indeterminate nodule categories (BC-1, ten nodules/BC-3, and four nodules), tissue diagnosis was found to be malignant in $5(35.7 \%)$ of 14 nodules. In the benign category (BC-2), 4 benign and 4 malignant nodules were detected after excision (Table 2). In these cases, the fact that rFNAB identified only one case in the malignant category (BC-6) and, in fact, 12 more cases of malignancy after excision made us think that rFNAB did not contribute to our BC-4 cases. In general, we interpreted that the rate of detecting malignancy of $r F N A B$ was low. In 29 nodules with RFNAB, a significant correlation was found between malignancy and advanced age (52.9), presence of nodules smaller than $2 \mathrm{~cm}$ and hypervascularization ( $\mathrm{p}=0.047, \mathrm{p}=0.047$, and $\mathrm{p}=0.030$, respectively). No significant association was found with other characteristics (Table 3). 
Table 1. Clinical-radiological-pathological characteristics of the cases

\begin{tabular}{|c|c|c|c|c|c|c|c|}
\hline$n=157$ & \multicolumn{2}{|c|}{ Total } & \multicolumn{2}{|c|}{ Benign $(n=96)$} & \multicolumn{2}{|c|}{ Malignant $(n=61)$} & $\mathbf{P}$ \\
\hline Female & 51 & $32.5 \%$ & 38 & $39.6 \%$ & 13 & $21.3 \%$ & \\
\hline Nodule size $2 \mathrm{~cm}$ and above & 70 & $44.6 \%$ & 52 & $54.2 \%$ & 18 & $29.5 \%$ & 0.002 \\
\hline Nodule size $(\mathrm{Med} \pm \mathrm{SD})$ & \multicolumn{2}{|c|}{$20.6 \pm 13.2$} & \multicolumn{2}{|c|}{$20.1 \pm 13.3$} & \multicolumn{2}{|c|}{$22.8 \pm 12.7$} & 0.063 \\
\hline \multicolumn{8}{|l|}{ Irreguler border } \\
\hline+ & 11 & $7.0 \%$ & 4 & $4.2 \%$ & 7 & $11.5 \%$ & 0.109 \\
\hline- & 146 & $93.0 \%$ & 92 & $95.8 \%$ & 54 & $88.5 \%$ & \\
\hline Solid & 92 & $58.6 \%$ & 55 & $57.3 \%$ & 37 & $60.7 \%$ & 0.677 \\
\hline Cystic-solid & 65 & $41.4 \%$ & 41 & $42.7 \%$ & 24 & $39.3 \%$ & \\
\hline \multicolumn{8}{|l|}{ Halo loss } \\
\hline+ & 21 & $13.4 \%$ & 16 & $16.7 \%$ & 5 & $8.2 \%$ & 0.129 \\
\hline- & 136 & $86.6 \%$ & 80 & $83.3 \%$ & 56 & $91.8 \%$ & \\
\hline \multicolumn{8}{|l|}{ Hypervascularization } \\
\hline+ & 7 & $4.5 \%$ & 1 & $1.0 \%$ & 6 & $9.8 \%$ & 0.014 \\
\hline- & 150 & $95.5 \%$ & 95 & $99.0 \%$ & 55 & $90.2 \%$ & \\
\hline \multicolumn{8}{|c|}{ Number of suspicious features (USG) } \\
\hline 0 & 41 & $26.1 \%$ & 28 & $29.2 \%$ & 13 & $21.3 \%$ & 0.364 \\
\hline 1 & 37 & $23.6 \%$ & 23 & $24.0 \%$ & 14 & $23.0 \%$ & \\
\hline 2 & 50 & $31.8 \%$ & 31 & $32.3 \%$ & 19 & $31.1 \%$ & \\
\hline
\end{tabular}

Suspicious Features; Hypoechogenicity, Solid structure, Microcalcification, Halo loss, Hypervascularisation.

Table 2. Comparison of rFNAB results of cases with tissue diagnosis

Excision diagnosis of rFNAB cases

\begin{tabular}{|c|c|c|c|c|c|c|}
\hline \multirow{3}{*}{$n=29$} & \multirow{2}{*}{\multicolumn{2}{|c|}{ rFNAB results }} & \multirow{2}{*}{\multicolumn{2}{|c|}{ Benign $(n=16)$}} & & \\
\hline & & & & & \multicolumn{2}{|c|}{ Malignant $(n=13)$} \\
\hline & $\mathbf{n}$ & $\%$ & $\mathbf{n}$ & $\%$ & $\mathbf{n}$ & $\%$ \\
\hline$B C-1$ & 10 & 34.5 & 7 & 43.8 & 3 & 23.1 \\
\hline$B C-2$ & 8 & 27.6 & 4 & 25.0 & 4 & 30.8 \\
\hline$B C-3$ & 4 & 13.8 & 2 & 12.5 & 2 & 15.4 \\
\hline BC-4 & 6 & 20.7 & 3 & 18.8 & 3 & 23.1 \\
\hline$B C-5$ & - & - & - & - & - & - \\
\hline BC-6 & 1 & 3.4 & 0 & 0.0 & 1 & 7.7 \\
\hline Total & 29 & 100 & 16 & 100 & 13 & 100 \\
\hline
\end{tabular}

rFNAB: Repeat fine-needle aspiration biopsy; BC: Bethesda category.

In cases without rFNAB, the close relationship between male gender and malignancy, which we observed in all cases, was also remarkable here $(p=0.034)$. The incidence of malignancy was higher in patients with nodules smaller than $2 \mathrm{~cm}$ in this group. As the nodule size increased, the frequency of being benign was found to be significantly higher $(p=0.011$ and $p=0.001$, respectively). Among the USG features, the low nodule echogenicity and the incidence of malignancy were 
Table 3. Comparison of characteristics of repeat fine-needle aspiration biopsy cases

\begin{tabular}{|c|c|c|c|c|c|c|c|}
\hline$n=29$ & \multicolumn{2}{|c|}{ Total } & \multicolumn{2}{|c|}{ Benign $(n=16)$} & \multicolumn{2}{|c|}{ Malignant $(n=13)$} & $\mathbf{P}$ \\
\hline Age $(\mathrm{Med} \pm \mathrm{SD})$ & \multicolumn{2}{|c|}{$47.0 \pm 14.6$} & \multicolumn{2}{|c|}{$42.2 \pm 12.5$} & \multicolumn{2}{|c|}{$52.9 \pm 15.3$} & 0.047 \\
\hline Female & 7 & $24.1 \%$ & 5 & $31.3 \%$ & 2 & $15.4 \%$ & 0.410 \\
\hline Male & 22 & $75.9 \%$ & 11 & $68.8 \%$ & 11 & $84.6 \%$ & \\
\hline Nodule size $2 \mathrm{~cm}$ and above & 17 & $58.6 \%$ & 12 & $75.0 \%$ & 5 & $38.5 \%$ & 0.047 \\
\hline Nodule size (Med \pm SD) & \multicolumn{2}{|c|}{$22.8 \pm 12.7$} & \multicolumn{2}{|c|}{$24.8 \pm 13.7$} & \multicolumn{2}{|c|}{$20.3 \pm 11.5$} & 0.199 \\
\hline Hypoecoic & 14 & $48.3 \%$ & 9 & $56.3 \%$ & 5 & $38.5 \%$ & 0.340 \\
\hline Iso-hyperecoic & 15 & $51.7 \%$ & 7 & $43.8 \%$ & 8 & $61.5 \%$ & \\
\hline \multicolumn{8}{|l|}{ Irreguler border } \\
\hline+ & 3 & $10.3 \%$ & 1 & $6.3 \%$ & 2 & $15.4 \%$ & 0.573 \\
\hline- & 26 & $89.7 \%$ & 15 & $93.8 \%$ & 11 & $84.6 \%$ & \\
\hline Solid & 13 & $44.8 \%$ & 8 & $50.0 \%$ & 5 & $38.5 \%$ & 0.534 \\
\hline Cystic-solid & 16 & $55.2 \%$ & 8 & $50.0 \%$ & 8 & $61.5 \%$ & \\
\hline \multicolumn{8}{|l|}{ Microcalcification } \\
\hline+ & 4 & $13.8 \%$ & 2 & $12.5 \%$ & 2 & $15.4 \%$ & 1.000 \\
\hline- & 25 & $86.2 \%$ & 14 & $87.5 \%$ & 11 & $84.6 \%$ & \\
\hline \multicolumn{8}{|l|}{ Halo loss } \\
\hline+ & 4 & $13.8 \%$ & 3 & $18.8 \%$ & 1 & $7.7 \%$ & 0.606 \\
\hline- & 25 & $86.2 \%$ & 13 & $81.3 \%$ & 12 & $92.3 \%$ & \\
\hline \multicolumn{8}{|l|}{ Hypervascularization } \\
\hline+ & 4 & $13.8 \%$ & 0 & $0.0 \%$ & 4 & $30.8 \%$ & 0.030 \\
\hline- & 25 & $86.2 \%$ & 16 & $100.0 \%$ & 9 & $69.2 \%$ & \\
\hline \multicolumn{8}{|c|}{ Number of suspicious features* (Ultrasonography) } \\
\hline 0 & 8 & $27.6 \%$ & 4 & $25.0 \%$ & 4 & $30.8 \%$ & 0.116 \\
\hline 1 & 9 & $31.0 \%$ & 4 & $25.0 \%$ & 5 & $38.5 \%$ & \\
\hline 2 & 6 & $20.7 \%$ & 6 & $37.5 \%$ & 0 & $0.0 \%$ & \\
\hline 3 & 3 & $10.3 \%$ & 1 & $6.3 \%$ & 2 & $15.4 \%$ & \\
\hline 4 & 3 & $10.3 \%$ & 1 & $6.3 \%$ & 2 & $15.4 \%$ & \\
\hline 5 & & & & & & & \\
\hline
\end{tabular}

*Suspicious Features; Hypoechogenicity, Solid structure, Microcalcification, Halo loss, Hypervascularization.

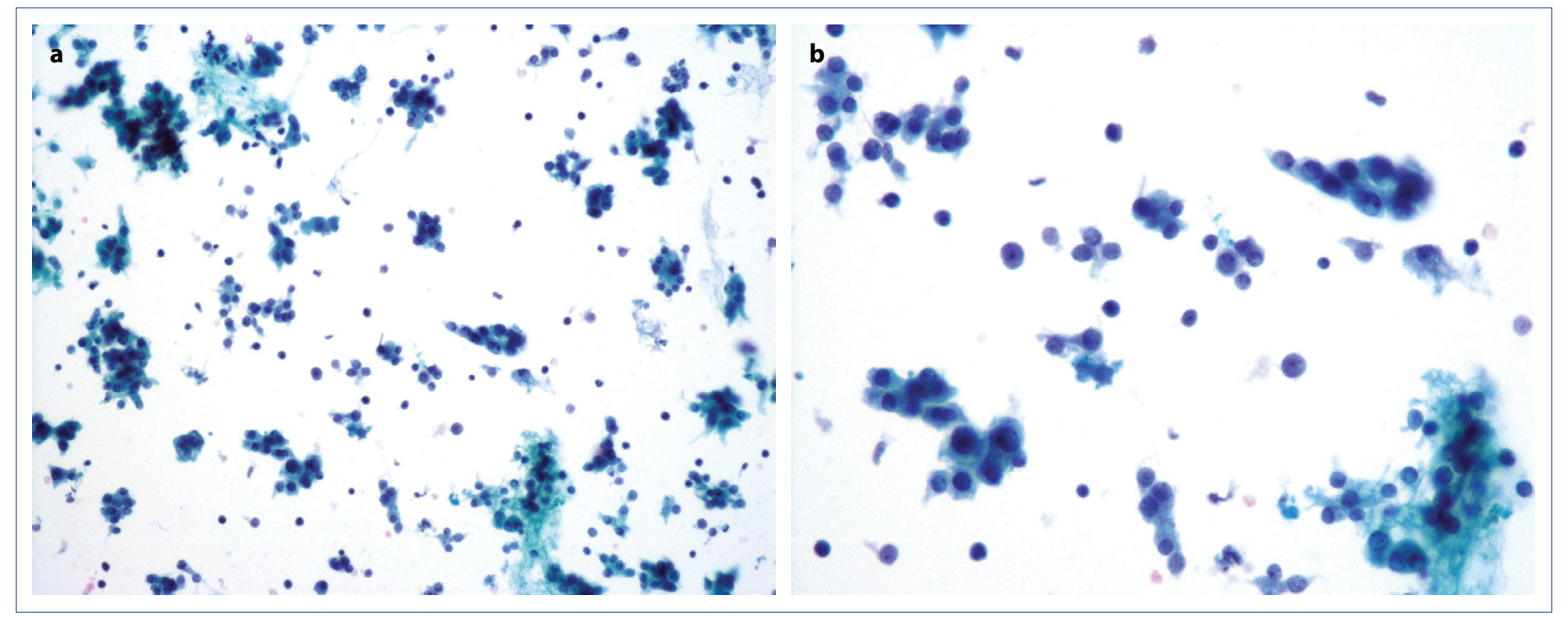

Figure 1. (a, b) An example of hypercellular fine-needle aspiration biopsy that does not contain colloids and consists mostly of micro-diameter follicles, FN/SFN (BC-4), LBC, PAP, $\times 200,400$. 
Table 4. Comparison of the characteristics of cases without repeat fine-needle aspiration biopsy

\begin{tabular}{|c|c|c|c|c|c|c|c|}
\hline$n=128$ & \multicolumn{2}{|c|}{ Total } & \multicolumn{2}{|c|}{ Benign $(n=80)$} & \multicolumn{2}{|c|}{ Malign $(n=48)$} & $\mathbf{P}$ \\
\hline Age (Med $\pm S D)$ & \multicolumn{2}{|c|}{$45.6 \pm 13.7$} & \multicolumn{2}{|c|}{$44.1 \pm 13.5$} & \multicolumn{2}{|c|}{$48.2 \pm 13.8$} & 0.100 \\
\hline Female & 44 & $34.4 \%$ & 33 & $41.3 \%$ & 11 & $22.9 \%$ & 0.034 \\
\hline Male & 84 & $65.6 \%$ & 47 & $58.8 \%$ & 37 & $77.1 \%$ & \\
\hline Nodule size $2 \mathrm{~cm}$ and above & 53 & $41.4 \%$ & 40 & $50.0 \%$ & 13 & $27.1 \%$ & 0.011 \\
\hline Nodule size $(\mathrm{Med} \pm \mathrm{SD})$ & \multicolumn{2}{|c|}{$20.1 \pm 13.3$} & \multicolumn{2}{|c|}{$22.1 \pm 14.2$} & \multicolumn{2}{|c|}{$26.8 \pm 11.0$} & 0.001 \\
\hline Hypoecoic & 67 & $52.3 \%$ & 36 & $45.0 \%$ & 31 & $64.6 \%$ & 0.032 \\
\hline Iso-hyperecoic & 61 & $47.7 \%$ & 44 & $55.0 \%$ & 17 & $35.4 \%$ & \\
\hline \multicolumn{8}{|l|}{ Irregular border } \\
\hline+ & 8 & $6.3 \%$ & 3 & $3.8 \%$ & 5 & $10.4 \%$ & 0.150 \\
\hline- & 120 & $93.8 \%$ & 77 & $96.3 \%$ & 43 & $89.6 \%$ & \\
\hline Solid & 79 & $61.7 \%$ & 47 & $58.8 \%$ & 32 & $66.7 \%$ & 0.372 \\
\hline Cystic-solid & 49 & $38.3 \%$ & 33 & $41.3 \%$ & 16 & $33.3 \%$ & \\
\hline \multicolumn{8}{|l|}{ Microcalcification } \\
\hline+ & 15 & $11.7 \%$ & 6 & $7.5 \%$ & 9 & $18.8 \%$ & 0.055 \\
\hline- & 113 & $88.3 \%$ & 74 & $92.5 \%$ & 39 & $81.3 \%$ & \\
\hline \multicolumn{8}{|l|}{ Halo loss } \\
\hline+ & 17 & $13.3 \%$ & 13 & $16.3 \%$ & 4 & $8.3 \%$ & 0.201 \\
\hline- & 111 & $86.7 \%$ & 67 & $83.8 \%$ & 44 & $91.7 \%$ & \\
\hline \multicolumn{8}{|l|}{ Hypervascularization } \\
\hline+ & 3 & $2.3 \%$ & 1 & $1.3 \%$ & 2 & $4.2 \%$ & 0.556 \\
\hline- & 125 & $97.7 \%$ & 79 & $98.8 \%$ & 46 & $95.8 \%$ & \\
\hline \multicolumn{8}{|c|}{ Number of suspicious features* (Ultrasonography) } \\
\hline 0 & 33 & $25.8 \%$ & 24 & $30.0 \%$ & 9 & $18.8 \%$ & 0.298 \\
\hline 1 & 28 & $21.9 \%$ & 19 & $23.8 \%$ & 9 & $18.8 \%$ & \\
\hline 2 & 44 & $34.4 \%$ & 25 & $31.3 \%$ & 19 & $39.6 \%$ & \\
\hline 3 & 19 & $14.8 \%$ & 11 & $13.8 \%$ & 8 & $16.7 \%$ & \\
\hline 4 & 4 & $3.1 \%$ & 1 & $1.3 \%$ & 3 & $6.3 \%$ & \\
\hline 5 & - & - & - & - & - & - & \\
\hline
\end{tabular}

*Suspicious Features; Hypoechogenicity, Solid structure, Microcalcification, Halo loss, Hypervascularisation.

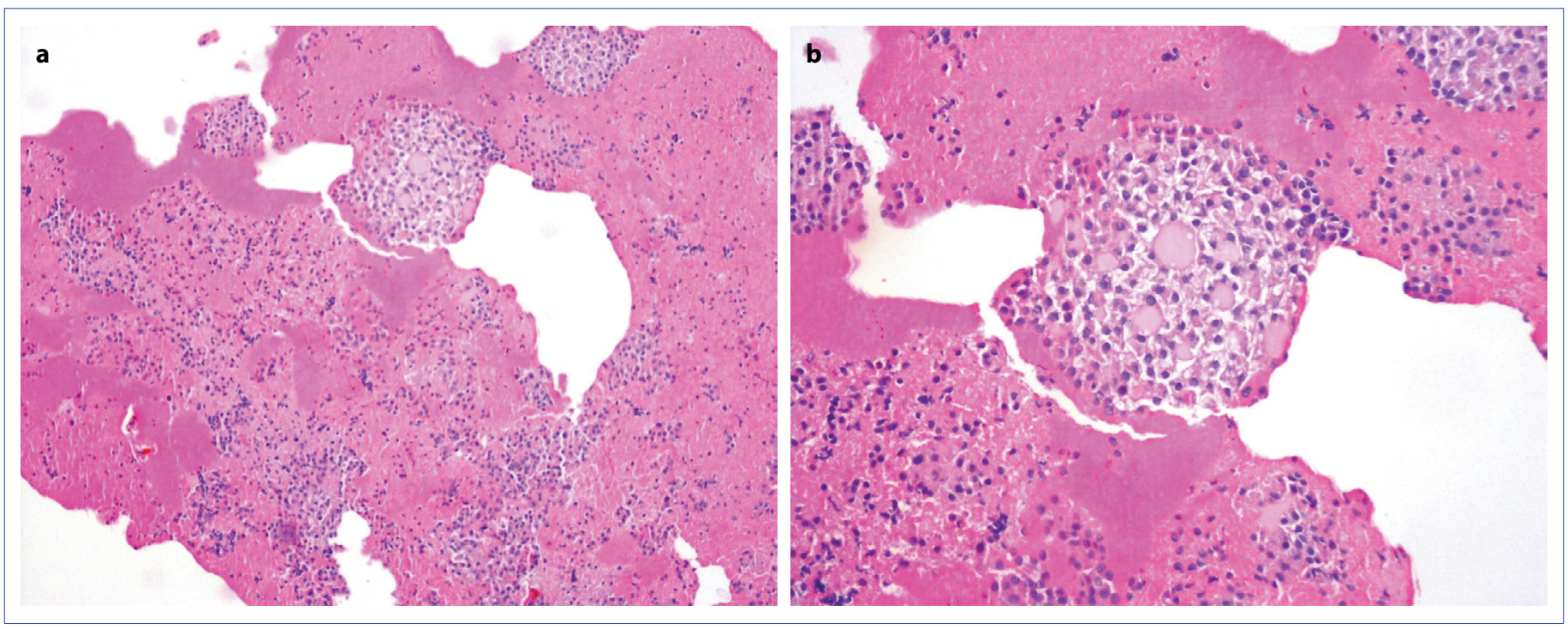

Figure 2. (a and b) Cell block section of hypercellular aspiration consisting mostly of oncocytic thyrocytes, partially poor in colloid, FN/SFN (BC-4), HEX40, 100. 
Table 5. Comparison of the characteristics of cases with and without rFNAB

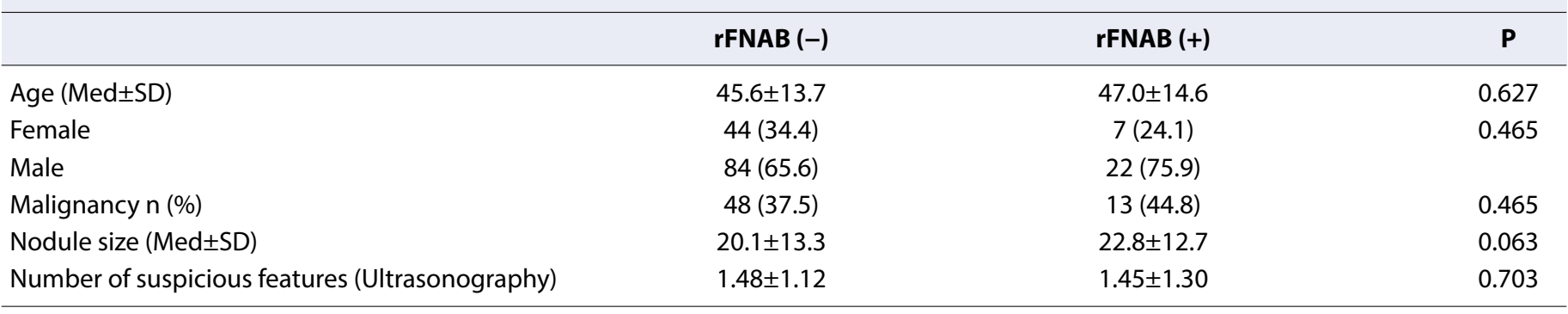

rFNAB: Repeat fine-needle aspiration biopsy.

Table 6. Histopathological diagnosis distribution of the cases

\begin{tabular}{lccc}
\hline $\mathbf{n = 1 5 7}$ & & $\mathbf{n}$ & $\%$ \\
\hline Diagnosis & & & \\
& Follicular adenoma & 54 & 34.4 \\
& Papillary microcarcinoma & 28 & 17.8 \\
& Nodular hyperplasia & 25 & 15.9 \\
& Papillary carcinoma classic variant & 14 & 8.9 \\
& Papillary carcinoma follicular variant & 11 & 7.0 \\
& Lymphocytic thyroiditis & 11 & 7.0 \\
& Follicular carcinoma & 7 & 4.4 \\
& Hurthle cell adenoma & 6 & 3.8 \\
Total & Anaplastic carcinoma & 1 & 0.6 \\
& Benign & 96 & 61.1 \\
& Malignant & 61 & 38.9 \\
\hline
\end{tabular}

found to be significant ( $p=0.032$ ). There were no significant statistics in terms of other clinical and radiological features and the frequency of malignancy (Table 4).

We compared nodules with and without rFNAB by looking at their clinical and radiological features and the frequency of malignancy. We could not find a significant relationship in any parameter (Table 5).

In the definitive histopathological diagnosis of nodules after excision, FA takes the first place with $34.4 \%$. If we add Hurthle cell adenoma (3.8\%), this ratio will be even higher. Papillary microcarcinoma ranks first with 28 nodules $(17.8 \%$ in all nodules) as the diagnosis of malignancy. Its frequency among malignant nodules was found to be much higher (28/61 nodules and $45.9 \%)$. Carcinomas of follicular nature were found less frequently (Table 6).

\section{Discussion}

Both the number of cases and the high resection rate are important in our series. Its advantageous feature is that it is designed on nodules whose clinical and USG features are known and have a definite pathological diagnosis. Among all nodules, our incidence of BC-4 cytology (5.1\%) was consistent with the literature range $(1-25 \%)$ and the overall mean (10\%). ${ }^{[11]}$ The high resection rate $(157 / 185$ nodules, $84.8 \%$ ) was one of the impressive features of our series. The literature range is $41.8-45 \% \cdot{ }^{[5]}$ However, there is a higher ratio of $77 \%$ in the current series. The general literature average is also stated as $69.7 \%{ }^{[11]}$ The probability of a nodule in the FN category to be neoplastic is $65-85 \% .{ }^{[7]}$ The majority of cases (up to 35\%) are not neoplasms, but rather hyperplastic proliferation of follicular cells, most commonly MNG proliferations. ${ }^{[2,3]}$ Our non-neoplastic lesions also had the most common MNG (15.9\%), the rate of all non-neoplastic lesions (+ lymphocytic thyroiditis, $7.0 \%$ ) was $22.9 \%$. Benign or malignant neoplasia was present in $77.1 \%$ of our cases. As stated in the literature, FA (34.4\%) was at the top of our neoplasia list. ${ }^{[17]}$ Although Bethesda reports the current ROM rate as 10-40\%[3] in this category, there are different results. Although there is a range of $22-50 \%$ in the literature, higher rates are available. ${ }^{[18]}$ An example of these high malignancy rates is the study of Maia et al. which reported $51.3 \%$ (exceeding Bethesda's 40\% upper limit). ${ }^{[19]}$ In a study evaluating malignancy rates in all BCS, the authors who found malignancy in half (50\%) of 42 BC-4 nodules suggested that the Bethesda system underestimated malignancy rates in $\mathrm{BC}-1,2,3,4$ categories. They also argued that there was no relationship between nodule size and malignancy rate in these cytopathological categories. ${ }^{[20]}$ Although our malignancy rate $(38.9 \%)$ was within the expected literature range $(25-40 \%)^{[3]}$ it was close to the upper limit. We think that our high rate of nodule excision plays an important role in this. Ultimately, our malignancy rate is based on nodules with a true and definitive histopathological diagnosis, rather than an estimate.

It has been determined that most of the malignant nodules of the FN category are follicular pattern carcinomas and significant portion is follicular variants of papillary carcino$\mathrm{ma} .^{[2]}$ Malignant nodules in this category are expected to be mostly FC. However, most of the malignancies (27-68\%) are interpreted histologically as PTC. The most important reason for this discrepancy is explained by the fact that follicular variants of papillary carcinoma and NIFTP, in partic- 
ular, are not fully developed throughout the entire nodule and the cellular characteristics of papillary carcinoma in the FNAB sample have not been demonstrated. ${ }^{[7]}$ In our cases, mostly papillary carcinoma and its variants (33.7\%) were found. Papillary microcarcinoma/carcinoma was the most common in malignant nodules in our cases. Subsequently, malignancy (FVPC and FC) with a follicular pattern was found. As in some studies, ${ }^{[21]}$ we did not include papillary microcarcinomas, which are considered to be more incidental in surgical pathology (in our series, it is in the second place after FA, 17.8\%) in the benign group. Had we done this, our malignancy rate would have declined to $21.1 \%$. To predict malignancy in BC-4 nodules, there are studies that find male gender, solid nodules larger than $3 \mathrm{~cm}$ or $4 \mathrm{~cm}$, some younger, and some older age risky. ${ }^{[22]}$ In our cases, we found a significant relationship with male gender and malignancy $(p=0.017)$. In the literature, there are results that are compatible ${ }^{[1,23-25]}$ with our data as well as those that are not. ${ }^{[21,25-27,29]}$ In our cases, malignancy was common in elderly patients (med.52.9) in the rFNAB group, and we found a statistically significant relationship $(p=0.047)$. These data were not detected in the group without rFNAB and in the group with all cases. Studies showing an increase in malignancy with $\mathrm{FN}$ have been reported to increase the risk generally over the age of $40-45$ years. ${ }^{[1,27]}$ However, there are some who claim that there is no advanced age relationship ${ }^{[21,23,25,26]}$ or, on the contrary, the frequency increases at young age. ${ }^{[24]}$ Interestingly, this study suggested that cancer risk decreases by 0.7 times for every 10 -year-old increase. These authors attributed this to the fact that thyroid nodules often result from increasing with age. ${ }^{[24]}$ Old data on nodule size in the literature were even more contradictory. There were those who thought that the large nodule size was at ROM or, on the contrary, benign nodules had a higher growth tendency. ${ }^{[21]}$ Current data more suggest that there is a relationship between size increase and malignancy in nodules with indetermined cytology. The relationship between nodule size and malignancy was shown in two separate meta-analysis studies with a large number of cases. In one study, it was emphasized that the risk increased in nodules larger than $3-4 \mathrm{~cm}$, and in the other, 2 $\mathrm{cm}$ threshold value did not increase the risk of cancer. ${ }^{[28]}$ In two older studies, it was shown that malignancy increases as the size of nodules in the FN cytology category increases. ${ }^{[1,23]}$ In our series, the frequency of benign nodules $2 \mathrm{~cm}$ and larger was significantly higher. This feature was evident in all nodules with or without rFNAB. In the group without RFNAB, as the size of the nodule increased, the characteristic of being benign increased (Tables 1, 3 and 4). In a study supporting our result, the frequency of benign nodules with large sizes was found to be significantly higher. ${ }^{[30]}$ In a meta-analysis study in which the USG features of thyroid nodules (14 criteria) were reviewed, it was reported that internal calcification was a high level of evidence for malignancy (especially for PC) and cystic-spongioform structure for benignity. It has been suggested that other USG features are low-to-moderate evidence and that nodule size does not have a precise predictive value in all $\mathrm{BCs} .{ }^{[31]}$ Among the nodules in our series, hypervascularization and hypoechogenicity were found as the most prominent USG features showing the relationship with malignancy. Malignancy was found in six out of seven hypervascularized nodules and in all four nodules in the rFNAB group, and it was statistically significant ( $p=0.014$, and $p=0.030$, respectively). We found malignancy in 31 (42.6\%) of 67 hypoechogenic nodules excised by direct surgery, "almost one in every two nodules" and the result was significant ( $p=0.032)$. In fact, the presence of microcalcification in our nodules can be interpreted in relation to malignancy because the $P$ value is very close to the significant statistic $(p=0.055)$. We could not find a significant relationship between other USG features to predict malignancy. In a recent study, there were data similar to ours, except for nodule size. In this study, the authors argued that hypervascularization, hypoechogenicity, microcalcification, solid structure, and nodules larger than $4 \mathrm{~cm}$ are predictive for malignancy and that unnecessary surgery can be reduced by $17 \%$ by applying them to nodules without any risk..$^{[11]}$ In another recent study, the authors showed that microcalcification and advanced age (over 45-years-old) are at ROM. ${ }^{[27]}$

There is no rFNAB recommendation for the management of $\mathrm{BC}-4$ nodules. Therefore, studies evaluating rFNAB in these nodules are rare. ${ }^{[10,12,13]}$ In a study evaluating the benefit of rFNAB in BC-3 and four nodules, three out of 15 BC-4 nodules (20\%) showed that the rFNAB result upgraded to a more precise category for malignancy ( $1 \mathrm{BC}-5$ and $2 \mathrm{BC}-6)$. These authors suggested that hemi-thyroidectomy for BC-3 and four nodules is not a desired management method and if surgical excision is to be performed in these nodules, rFNAB contributes to the decision of total thyroidectomy. ${ }^{[13]}$ Before Bethesda, Baloch et al. questioned the efficacy of rFNAB in indeterminate (available equivalent $B C-3,4$ ) nodules (103 nodules). They determined excision diagnoses (8 NG, 7 FA, 9 PC) of 24 of 33 nodules with rFNAB diagnosis $\mathrm{FN}$. Of the nodules scattered to other cytology diagnoses, 24 were excised and 9 PC and 1 lymphoma were found in these. They recommended ultrasound-guided FNAB repeat in all of these nodules, as they found a high rate of malignancy in initially indetermined nodules on surgical excisions of rFNAB cases ( 19 out of 48 cases had malignancy, $39.6 \%) .{ }^{[12]}$ Contrary to the current recommendation, a recent study suggested rFNAB to confirm PTC in BC-3,4 nod- 
ules in the presence of suspicious USG features. It was recommended to avoid rFNAB in nodules without these USG features. The authors based their recommendations on the idea that $r F N A B$ is not effective in detecting $F C$ and poorly differentiated carcinomas. ${ }^{[30]}$ In a study evaluating multiple FNAB repeats in BC- 4 nodules, 90 nodules were examined. In the $2^{\text {nd }} F N A B, 53$ of these were again determined as BC-4. 14 were operated and ten found benign (7 FA) or malignant neoplasia (2 PC, 1 FC). These authors showed in their 3rd and 4th FNAB results that nodules had a high rate of neoplasia with BC-4 and they argued that direct surgery and patient management are an appropriate practice in nodules whose first result was BC-4. They reported that BC-4 cytology has a high positive predictive value (73\%). ${ }^{[10]}$ In our series, we thought that rFNAB was not beneficial enough in $B C-4$ nodules because, unlike these authors, we focused on rFNAB's ability to detect malignancy. In our series, there was no significant difference between malignancy and other clinical-radiological features of nodules in the group with and without rFNAB (Table 5). Looking at the Bethesda distribution of the rFNAB group again, we found that only one of the 29 nodules (BC-6, 3.4\%) detected malignancy. Malignancy was detected after excision in $12(42.8 \%)$ of 28 nodules reclassified in other categories (BC-1,2,3,4, non-diagnostic, benign, AUS/FLUS, FN/SFN). Of the 29 BC-4 nodules to which we applied rFNAB, seven $(24.1 \%)(6$ BC-4, 1 BC-6) were reclassified to the group that could be operated according to ATA criteria. In four of these seven cases (57.1\%), malignancy was detected after excision. The data showed that rFNAB administration failed to detect malignancy in BC-4 nodules in our series. The distribution of certain malignancy subgroups in our nodules, "papillary microcarcinoma, PCFV, whose nuclear features are insufficient in cytology, FC, for which capsular or vascular invasion should be shown in the tissue for diagnosis" were effective in this.

We think that rFNAB will not be effective in reducing the gray zone feature, which can be interpreted as the nature of BC- 4 cases. It is already in this direction in current guides at the moment. In this case, it should be emphasized that suspicious USG features, clinical factors, and personal characteristics can be evaluated together and unnecessary surgery can be reduced. The main suspicious USG features in our series were hypervascularity, hypoechogenicity, and microcalcification. We found male gender-malignancy relationship to be significant as a clinical factor.

\section{Conclusion}

We recommend careful review of patients with hypervascular, hypoechogenic, and microcalcific BC-4 nodules (male gender and old age at greater risk). Because of the serious risk of malignancy, patients with these features should be considered to have a frozen section into the nodule during the operation and be prepared for its management with total thyroidectomy.

\section{Disclosures}

Ethics Committee Approval: This study approved by Sisli Etfal Health Application and Research Center Ethics Committee. (Date: 01.12.2020-Number: 3027)

Peer-review: Externally peer-reviewed.

Conflict of Interest: No conflict of interest is declared by the authors.

Authorship Contributions: Concept - R.U., B.Y.O.; Design - R.U., D.T., N.A., C.S, B.Y.O., M.U., F.K.; Supervision - R.U., B.Y.O., M.U., F.K.; Materials - R.U., B.Y.O.; Data collection \&/or processing - R.U., D.T., B.Y.O., M.U., F.K.; Analysis and/or interpretation - R.U., D.T., B.Y.O.; Literature search - R.U.; Writing - R.U.; Critical review - R.U., B.Y.O., M.U., F.K.

\section{References}

1. Baloch ZW, Fleisher S, LiVolsi VA, Gupta PK. Diagnosis of "follicular neoplasm": a gray zone in thyroid fine-needle aspiration cytology. Diagn Cytopathol 2002;26:41-4. [CrossRef]

2. Cibas ES, Ali SZ; NCI Thyroid FNA State of the Science Conference. The Bethesda System for Reporting Thyroid Cytopathology. Am J Clin Pathol 2009;132:658-65. [CrossRef]

3. Cibas ES, Ali SZ. The 2017 Bethesda System for reporting thyroid cytopathology. Thyroid 2017;27:1341-6. [CrossRef]

4. Bongiovanni M, Spitale A, Faquin WC, Mazzucchelli L, Baloch ZW. The Bethesda System for Reporting Thyroid Cytopathology: a meta-analysis. Acta Cytol 2012;56:333-9. [CrossRef]

5. Harvey AM, Mody DR, Amrikachi M. Thyroid fine-needle aspiration reporting rates and outcomes before and after Bethesda implementation within a combined academic and community hospital system. Arch Pathol Lab Med 2013;137:1664-8. [CrossRef]

6. Alshaikh S, Harb Z, Aljufairi E, Almahari SA. Classification of thyroid fine-needle aspiration cytology into Bethesda categories: An institutional experience and review of the literature. Cytojournal 2018;15:4. [CrossRef]

7. Henry MR, Westra WH, Krane JF, Schmitt F. Follicular neoplasm/ suspicious for a follicular neoplasm. In: Ali S, Cibas E, editors. The Bethesda System for Reporting Thyroid Cytopathology. Springe, Cham; 2017. p. 71-80. [CrossRef]

8. Haugen BR, Alexander EK, Bible KC, Doherty GM, Mandel SJ, Nikiforov YE, et al. 2015 American Thyroid Association Management Guidelines for adult patients with thyroid nodules and differentiated thyroid cancer: The American Thyroid Association Guidelines Task Force on thyroid nodules and differentiated thyroid cancer. Thyroid 2016;26:1-133. [CrossRef]

9. Ustun B, Chhieng D, Van Dyke A, Carling T, Holt E, Udelsman R, et al. Risk stratification in follicular neoplasm: a cytological assess- 
ment using the modified Bethesda classification. Cancer Cytopathol 2014;122:536-45. [CrossRef]

10. Stanek-Widera A, Biskup-Frużyńska M, Zembala-Nożyńska $E$, Półtorak S, Śnietura M, Lange D. Suspicious for follicular neoplasm or follicular neoplasm? The dilemma of a pathologist and a surgeon. Endokrynol Pol 2016;67:17-22. [CrossRef]

11. Kuru B, Kefeli M. Risk factors associated with malignancy and with triage to surgery in thyroid nodules classified as Bethesda category IV (FN/SFN). Diagn Cytopathol 2018;46:489-94. [CrossRef]

12. Baloch Z, LiVolsi VA, Jain P, Jain R, Aljada I, Mandel S, et al. Role of repeat fine-needle aspiration biopsy (FNAB) in the management of thyroid nodules. Diagn Cytopathol 2003;29:203-6. [CrossRef]

13. Jooya A, Saliba J, Blackburn A, Tamilia M, Hier MP, Mlynarek A, et al. The role of repeat fine needle aspiration in the management of indeterminate thyroid nodules. J Otolaryngol Head Neck Surg 2016;45:51. [CrossRef]

14. Allen L, Al Afif A, Rigby MH, Bullock MJ, Trites J, Taylor SM, et al. The role of repeat fine needle aspiration in managing indeterminate thyroid nodules. J Otolaryngol Head Neck Surg 2019;48:16.

15. Kundel HL, Polansky M. Measurement of observer agreement. Radiology 2003;228:303-8. [CrossRef]

16. Shin JH, Baek JH, Chung J, Ha EJ, Kim JH, Lee YH, et al; Korean Society of Thyroid Radiology (KSThR) and Korean Society of Radiology. Ultrasonography diagnosis and imaging-based management of thyroid nodules: Revised Korean Society of Thyroid Radiology Consensus Statement and Recommendations. Korean J Radiol 2016;17:370-95. [CrossRef]

17. Li W, Sciallis A, Lew M, Pang J, Jing X. Implementing noninvasive follicular thyroid neoplasm with papillary-like nuclear features may potentially impact the risk of malignancy for thyroid nodules categorized as AUS/FLUS and FN/SFN. Diagn Cytopathol 2018;46:148-53. [CrossRef]

18. Mahajan S, Srinivasan R, Rajwanshi A, Radotra B, Panda N, Dey $P$, et al. Risk of malignancy and risk of neoplasia in the bethesda indeterminate categories: study on 4,532 thyroid fine-needle aspirations from a single institution in India. Acta Cytol 2017;61:103-10. [CrossRef]

19. Maia FF, Matos PS, Pavin EJ, Zantut-Wittmann DE. Thyroid imaging reporting and data system score combined with Bethesda system for malignancy risk stratification in thyroid nodules with indeterminate results on cytology. Clin Endocrinol (Oxf) 2015;82:439-44. [CrossRef]
20. Deniwar A, Hambleton C, Thethi T, Moroz K, Kandil E. Examining the Bethesda criteria risk stratification of thyroid nodules. Pathol Res Pract 2015;211:345-8. [CrossRef]

21. Macias CA, Arumugam D, Arlow RL, Eng OS, Lu SE, Javidian P, et al. A risk model to determine surgical treatment in patients with thyroid nodules with indeterminate cytology. Ann Surg Oncol 2015;22:1527-32. [CrossRef]

22. Dean DS, Gharib H. Fine-Needle Aspiration Biopsy of the Thyroid Gland. 2015 Apr 26. In: Feingold KR, Anawalt B, Boyce A, Chrousos G, de Herder WW, Dhatariya K, , editors. Endotext [Internet]. South Dartmouth (MA): MDText.com, Inc.; 2000. [CrossRef]

23. Tuttle RM, Lemar H, Burch HB. Clinical features associated with an increased risk of thyroid malignancy in patients with follicular neoplasia by fine-needle aspiration. Thyroid 1998;8:377-83.

24. Schlinkert RT, van Heerden JA, Goellner JR, Gharib H, Smith SL, Rosales RF, et al. Factors that predict malignant thyroid lesions when fine-needle aspiration is "suspicious for follicular neoplasm". Mayo Clin Proc 1997;72:913-6. [CrossRef]

25. Lee SH, Baek JS, Lee JY, Lim JA, Cho SY, Lee TH, et al. Predictive factors of malignancy in thyroid nodules with a cytological diagnosis of follicular neoplasm. Endocr Pathol 2013;24:177-83.

26. Gulcelik NE, Gulcelik MA, Kuru B. Risk of malignancy in patients with follicular neoplasm: predictive value of clinical and ultrasonographic features. Arch Otolaryngol Head Neck Surg 2008;134:1312-5.

27. Oz B, Doğan S, Emek E, Akyüz M, Akcan A, Sözüer E, et al. Predictive factors of malignancy in cytology of indeterminate follicular and hurthle cell neoplasms of the thyroid gland. Int Surg 2018;103:9-14.

28. Kiernan CM, Solórzano CC. Bethesda category III, IV, and V thyroid nodules: can nodule size help predict malignancy? J Am Coll Surg 2017;225:77-82. [CrossRef]

29. Saiegh L, Shechner C, Dickstein G, Sheikh-Ahmad M, Reut M, Odeh $M$, et al. Role of cytological and ultrasonographic features in predicting the risk of malignancy in thyroid nodules with indeterminate cytology. Minerva Endocrinol 2014;39:43-52.

30. Li F, Pan D, Wu Y, Peng J, Li Q, Gui X, et al. Ultrasound characteristics of thyroid nodules facilitate interpretation of the malignant risk of Bethesda system III/IV thyroid nodules and inform therapeutic schedule. Diagn Cytopathol 2019;47:881-9. [CrossRef]

31. Brito JP, Gionfriddo MR, AI Nofal A, Boehmer KR, Leppin AL, Reading $C$, et al. The accuracy of thyroid nodule ultrasound to predict thyroid cancer: systematic review and meta-analysis. J Clin Endocrinol Metab 2014;99:1253-63. [CrossRef] 